\title{
Caesarean myomectomy in a cervical fibroid: a brief communications
}

\begin{abstract}
Cervical fibroid in pregnancy is a rare entity. They present a variety of clinical challenges to the care giving gynaecologist. We are presenting a case of sessile cervical fibroid in the supravaginal portion being managed during caesarean and decision making points are discussed in detail.
\end{abstract}

Volume 2 Issue I - 2017

\begin{abstract}
Chaithra TM, Leena GP, Urmila Soman, Ratnavali Menon

Department of Obstetrics and Gynecology, Med Heaven
\end{abstract} hospital, India

Correspondence: Chaithra TM, Department of obstetrics and gynaecology, Mediheaven hospital,Aluva, Ernakulum, India, Tel +919645948022, Email drchaithralijesh@gmail.com

Received: January 07, 2017| Published: March 06, 2017

\section{Introduction}

Uterine myoma is a common gynaecological problem occurring in $20-50 \%$ of women, of late reproductive age. A majority of myomas are seen in uterine corpus. Cervical myomas account for less than $5 \%$ of uterine myomas. ${ }^{1}$ The prevalence of uterine myomas during pregnancy is estimated to be $0.3 \%$ to $2.6 \%{ }^{2}$ Compared to uterine corpus, cervical myomas pose a challenge due to its close relation with other organs like bladder, ureter and rectum. The surgical approach needs to be modified in each case. Surgical difficulties associated with these cases are poor access to myoma, difficulty in suturing and repairs, increased blood loss and distortion of the vital neighbouring structures in the pelvic cavity, making it vulnerable to injuries. The pregnancy poses a unique challenge of pregnancy related changes in fibroids and increased vascularity of the organ, making caesarean myomectomy a complicated procedure.

\section{Case report}

Cervical fibroids, both in pregnant and non pregnant status are a clinically challenging situation for surgeons. We are discussing a case of 32 year female with term pregnancy incidentally detected to have a sessile cervical fibroid during her antenatal scans which had remained of the same size $(6.5 \times 5 \mathrm{~cm})$ (Figure 1) throughout her pregnancy as usually happens in $70-80 \%$ of cases. The lady was asymptomatic. On examination a bulge was seen in the anterior upper vagina, pushing the cervix posteriorly. The term ultrasound showed $6 \times 5 \mathrm{~cm}$ fibroid in the supravaginal portion of the cervix (intracervical type) just below internal OS. Since she had a history of a previous caesarean section with cervical fibroid, she was posted for elective caesarean at 39 completed wks. The questions to be answered at this point are
a. Whether to do a concurrent caesarean myomectomy?
b. Whether to proceed vaginally or abdominally?
c. Will a tourniquet help in reducing the blood supply to cervical myoma, if so at what level?

Review of literature at this point said myomectomy during caesarean section could be generally recommended. The decision should be carefully taken in presence of surgical expertise and tertiary level care facilities. Depending on size and location of myomas, the associated risks are similar to those of isolated caesarean section. ${ }^{3}$ Since lower uterine segment was free of a fibroid, she was delivered by a lower uterine segment transverse incision. After caesarean, an attempt was made for cervical examination through the hysterectomy wound, a $6.5 \times 5 \mathrm{~cm}$ sessile fibroid occupying whole of the anterior lip of cervix was felt. The challenge here was, fibroid couldn't be reached easily or seen through the incision. The question, whether a vaginal examination will help in myomectomy? Was kept in mind. The diluted vasopressin injection was injected into the uterus. Bladder was dissected from vesicovaginal fascia (Figure 2) using mayo's scissors till the lower end of the cervix. Then the cervix was hooked up using left finger inside the cervical canal keeping in mind the location of the fibroid and its relation to the bladder and vagina, pushing the bladder safely down. A transverse incision was made in the anterior vaginal wall and then cervicotomy was done to reach the myoma. The myoma was enucleated (Figure 3) which weighed 100 gms. Myoma bed was sutured in 2 layers (Figure 4). The total blood loss during the procedure was less than $400 \mathrm{cc}$. The preoperative haemoglobin was $12 \mathrm{gm} / \mathrm{dl}$ and postoperative was $10.9 \mathrm{gm} / \mathrm{dl}$. The patient was hospitalised for 5 days as in case of a routine caesarean section. Post-operative period was uneventful. At one year follow up patient is asymptomatic and ultrasound is a normal study.

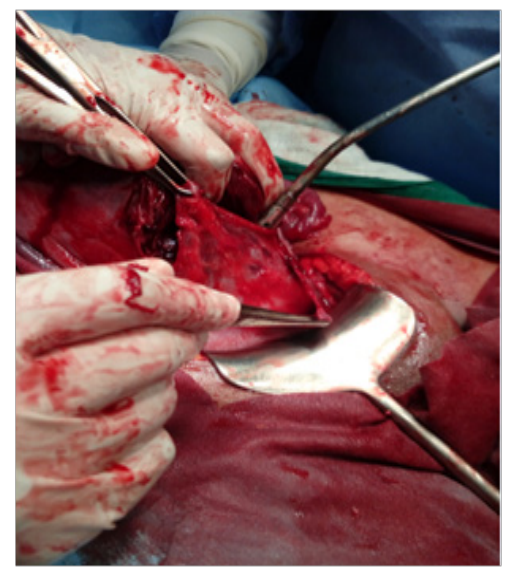

Figure I Vesicovaginal fascia dissection. 


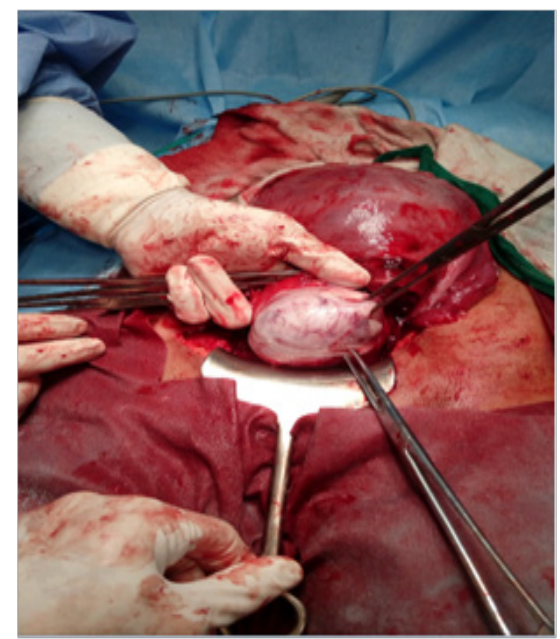

Figure 2 Cervical fibroid hooked out with fingers in hysterotomy incision.

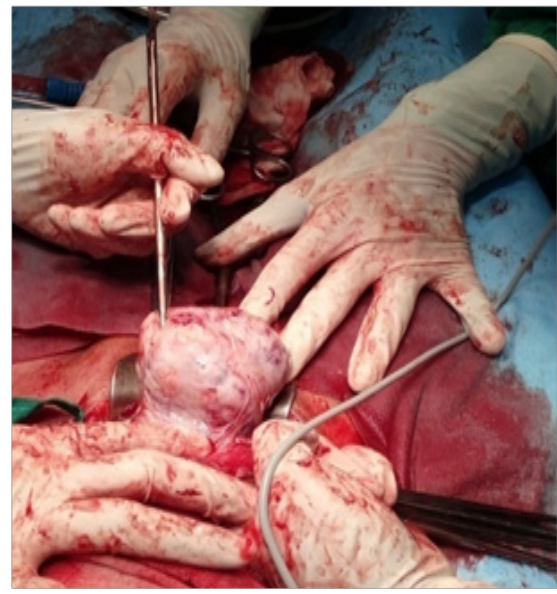

Figure 3 Myomectomy in progress.

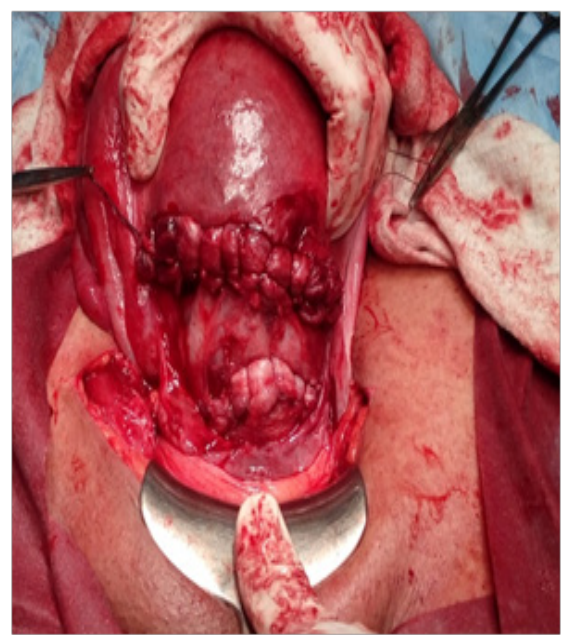

Figure 4 Incision lines at the end of procedure.

The clinical challenges are

i. To access the fibroid, extensive bladder dissection in pregnancy can be associated with massive haemorrhage, which was kept to a minimum by staying in correct pubocervical and by infiltrating diluted vasopressin ii. It is a tumour deep seated in the pelvis and was brought out by hooking cervix through the caesarean hysterectomy incision

iii. By attempting the steps of surgery in scientifically correct planned manner after review of literature and discussing with eminent experts in this field (surgery is $70 \%$ cerebral and 30\% manual).

We could accomplish the procedure with least morbidity in same setting as elective caesarean, avoiding one more surgery in the future and good obstetric future to the patient.

\section{Discussion}

Caesarean myomectomy in carefully selected and well planned manner is a safe procedure. In this article we are discussing particularly on cervical fibroids. Procedure should be planned keeping in mind size, location, type of fibroid and associated complications.

Less than $5 \mathrm{~cm}$, pedunculated fibroids in the infravaginal portion of the cervix are easy to access vaginally. More than $5 \mathrm{~cm}$ deep seated, intramural tumours may be posted electively for a non pregnant status. Sessile tumours from supravaginal portion of the cervix to be accessed from laparotomy incision. Myomas from anterior lip of the cervix can be accessed by pushing the bladder down by dissecting pubocervical fascia and transverse hysterotomy incision is preferred for myomectomy. Myomas from posterior lip of the cervix can be accessed by dissecting the denoviller's fascia and rectum off the myoma and making an incision on the most prominent bulge in the pouch of douglas vaginal wall and then on the myoma capsule and myoma enucleated. The incision was closed in 2layers. With careful patient selection, adequate experience, and efficient haemostatic measures, the procedure appears to be safe.

Some authors supported that the specific operative techniques such as tourniquet, uterine artery ligation, and pursestring suture are helpful to limit intraoperative bleeding during caesarean myomectomy.,5 Though, we did not use aforementioned techniques in present case, diluted vasopressin injection, correct surgical plane of dissection, double layered sutures, intraopeartive and postoperative uterotonic agents were effective in haemostasis.

Three categories of interventions have been identified: interventions on uterine vessels (laparoscopic uterine artery dissection, uterine artery embolization, paracervical mechanical tourniquet and hormonal tourniquets such as vasopressin and terlipressin); uterotonics such as ergometrine, oxytocin, misoprostol, and sulprostone; myoma dissection techniques, which include the use of laser and chemical dissectors such as sodium-2-mercaptoethane suffocate. However, the study of Sapmaz ${ }^{6}$ reported that bilateral uterine artery obliteration and the tourniquet both showed a similar efficacy in controlling intraoperative blood loss during caesarean myomectomy, but uterine artery obliteration was preferable to a tourniquet in preventing blood loss postoperatively. Another systematic review ${ }^{7}$ showed that the greatest effect on blood loss during myomectomy was recorded by a study that combined the occlusion of the uterine and ovarian arteries using tourniquets prior to myomectomy. So, the effectiveness of various techniques to be used to minimize the risk of bleeding is still the subject of study.

In case of large fibroids $>5 \mathrm{~cm}$, it's suggested to involve Interventional radiology department, to prophylactically catheterise uterine artery and proceed with embolistaion as and when necessary. This article information can be used for counselling women 
requesting concurrent caesarean myomectomy for cervical fibroids. In some selected cases it is possible initially to manage the patient conservatively hoping that the fibroid degenerates by spontaneous thrombosis of its feeding blood vessels making myomectomy easier to perform and so myomectomy can be delayed following delivery as these fibroids decrease in size making it easier to remove them. ${ }^{8}$ We should weigh the advantages and expertise available in each case for caesarean myomectomy. Large randomized trials are needed to guide decisions as to the best clinical practice regarding myomectomy during caesarean delivery. ${ }^{9}$

\section{Conclusion}

Caesarean myomectomy allows women to have a better obstetric outcome in future pregnancies. It relieves symptoms associated with fibroids and negates the need for later surgery follow-ups for the fibroid after delivery. In cervical fibroids additional care to be taken to protect vital organs.

\section{Acknowledgements}

None.

\section{Conflict of interest}

Author declares that there is no conflict of interest.

\section{References}

1. Patel P, Banker M, Munshi S, et al. Handling cervical myomas. $J$ Gynecol Endosc Surg. 2011;2(1):30-32.
2. Kaymak O, Ustunyurt E, Okyay RE, et al. Myomectomy during Cesarean section. Int J Gynecol Obstet. 2005;89(2):90-93.

3. Hassiakos D, Christopoulos P, Vitoratos N, et al. Myomectomy during cesarean section: a safe procedure? Annals of the New York Academy of Sciences. 2006;1092:408-413.

4. Klatsky PC, Tran ND, Caughey AB, et al. Fibroids and reproductive outcomes: a systematic literature review from conception to delivery. Am J Obstet Gynecol. 2008;198(4):357-366.

5. Shavell VI, Thakur M, Sawant A, et al. Adverse obstetric outcomes associated with sonographically identified large uterine fibroids. sFertil Steril. 2012;97(1):107-110.

6. Sapmaz E, Celik H, Altungil A. Bilateral ascending uterine artery ligation vs. tourniquet use for hemostasis in caesarean myomectomy. A comparison. J Reprod Med. 2003;48(12):950-954.

7. Kongnyuy EJ, Vanden Broek, Wiysonge CS. A systematic review of randomized controlled trials to reduce hemorrhage during myomectomy for uterine fibroids. Int J of Gynecology and Obstetrics. 2008;100(1):4-9.

8. Remon K, Mark M. Management of Cervical Fibroid during the Reproductive Period. Case Reports in Obstetrics and Gynecology. 2013;2013(2013):3.

9. Awoleke JO. Myomectomy during Caesarean Birth in Fibroid-Endemic, Low-Resource Settings. Obstetrics and Gynecology Int. 2013;2013:520834. 